\title{
Chromatin remodeling resets the immune system to protect against autoimmune
}

\section{diabetes in mice}

Running title: Epigenetic control of diabetes

Tejas Patel ${ }^{1}$, Vasu Patel ${ }^{1}$, Rajvir Singh ${ }^{1}$, and Sundararajan Jayaraman ${ }^{1,2}$

${ }^{1}$ Department of Surgery, ${ }^{2}$ Department of Medicine, College of Medicine, University of Illinois at Chicago, Chicago, IL 60612

Correspondence to: Sundararajan Jayaraman, Dept. of Medicine, COMRB 3168, 909 South Wolcott Avenue, M/C 719, University of Illinois at Chicago, College of Medicine, Chicago, IL 60612, USA. Phone: 312-355-5133; Fax: 312-996-2242;

e-mail: anue2468@uic.edu 


\section{ABSTRACT}

Epigenetic alteration of the genome has been shown to provide palliative effects in mouse models of certain human autoimmune diseases. We have investigated whether chromatin remodeling could provide protection against autoimmune diabetes in NOD mice. Treatment of female mice during the transition from prediabetic to diabetic stage (18-24 weeks of age) with the well-characterized histone deacetylase inhibitor, Trichostatin A effectively reduced the incidence of diabetes. However, similar treatment of overtly diabetic mice during the same time period failed to reverse the disease.

Protection against diabetes was accompanied by histone hyperacetylation in pancreas and spleen, enhanced frequency of $\mathrm{CD} 4{ }^{+} \mathrm{CD} 2 \mathrm{~L}^{+}$cells in the spleen, reduction in cellular infiltration of islets, restoration of normoglycemia and glucose-induced insulin release by beta cells. Activation of splenic T lymphocytes derived from protected mice in vitro with pharmacological agents that bypass the antigen receptor or immobilized anti-CD3 antibody resulted in enhanced expression of Ifng mRNA and protein without altering the expression of Il4, Il17, Ill8, Inos, and Tnfa genes nor the secretion of IL-2, IL-4, IL-17, and TNF- $\alpha$ proteins. Consistently, expression of the transcription factor involved in Ifng transcription, Tbet/Tbx21 but not Gata3 and Rorgt, respectively required for the transcription of $I l 4$ and $I l 17$, was upregulated in activated splenocytes of protected mice. These results indicate that chromatin remodeling can lead to amelioration of diabetes by employing multiple mechanisms including differential gene transcription. Thus, epigenetic modulation could be a novel therapeutic approach to block the transition from benign to frank diabetes.

KEY WORDS: Epigenetics, type 1 diabetes, interferon gamma gene, T regulatory cells. 


\section{INTRODUCTION}

Epigenetics, heritable changes in gene expression without altering the DNA sequence, involves DNA methylation and chromatin remodeling by phosphorylation, methylation, sumoylation, ubiquitination, and acetylation of histones ${ }^{1}$. Reversible acetylation of the $\varepsilon$-amino group of lysine in the histone tails by histone acetyl transferases and deacetylation by histone deacetylases (HDAC) are the best-characterized post-translational modifications of histones. Hyperacetylated histones are correlated with transcriptional permissiveness whereas hypoacetylated histones mediate gene repression ${ }^{1}$. Small molecule HDAC inhibitors are major tools for studying the correlation between overall chromatin modifications and cellular functions ${ }^{2}$. The HDAC inhibitors are often used to specifically inhibit the HDAC activity. Inhibition of HDAC activity in vitro increases histone acetylation within 2-4 h of treatment with HDAC inhibitors including Trichostatin A (TSA), and consequently induces up- and down-regulation of genes ${ }^{3-4}$. The HDAC inhibitor mediated regulation of a small portion of genes (5-20\%) is dependent on the cell type, dose and type of inhibitors used, suggesting that chromatin remodelling by HDAC inhibitors is a gene-specific event with a variable transcriptional outcome $\mathrm{e}^{2-4}$.

TSA, an antibiotic derived from Streptomyces $s p$. is one of the most potent and best-characterized HDAC inhibitors and it inhibits both class I (HDAC 1-3, and -8) and class II (HDAC 4-7, and -9) HDAC family members ${ }^{2}$. Treatment of immune cells in vitro with TSA has been shown to suppress the expression of genes involved in immune responses, such as interleukin-2 (IL-2) ${ }^{5}$, IL-6, IL-10, and IL-12 ${ }^{6}, \mathrm{CD} 25^{7}$, and CD154 $4^{7-8}$. In addition, TSA has been shown to upregulate the expression of interferon-gamma (IFN- 
$\gamma)$ in human lupus T cells in vitro ${ }^{8}$. While these studies indicate that HDAC inhibition can modulate the expression of cytokines in $\mathrm{T}$ lymphocytes stimulated in vitro, it not clear whether HDAC inhibitors can reprogram the T-cells to express altered cytokine profile in vivo. Recent studies indicate that treatment of normal ${ }^{9}$ and autoimmune prone mice ${ }^{10}$ intensely with TSA could increase both the number and function of $\mathrm{CD} 4^{+} \mathrm{CD} 25^{+} \mathrm{FoxP} 3^{+}$ $\mathrm{T}$ regulatory cells. However, it remains to be determined whether hyperacetylation can influence other T regulatory subsets also. The utility of the HDAC inhibitors including TSA to ameliorate autoimmune $\operatorname{lupus}^{6}$, experimental colitis ${ }^{11}$, airway hyperreactivity ${ }^{12}$, and experimental autoimmune encephalomyelitis ${ }^{13}$ in mouse models has been demonstrated. A preliminary investigation suggested the usefulness of the HDAC inhibitor FR901228 in a very small number $(\mathrm{n}=3)$ of newly diagnosed diabetic mice ${ }^{7}$. However, it is not clear whether epigenetic modulation could be useful in preventing the onset of autoimmune diabetes. Here, we investigated this possibility and unraveled some of the underlying mechanisms involved in protection against autoimmune diabetes by chromatin remodeling. 


\section{RESULTS}

\section{Amelioration of autoimmune diabetes by TSA treatment}

The efficacy of HDAC inhibition to protect female NOD mice against the naturally occurring autoimmune diabetes was determined by administering $500 \mu \mathrm{g}$ of TSA/kg body weight s.c. at weekly intervals. Cumulative data obtained from five experiments indicate that TSA treatment between 18 and 24 weeks $(n=68)$ but not at earlier time points provided long-term protection against diabetes (Figure 1a). Protection was exerted by TSA since administration of the vehicle, dimethyl sulfoxide (DMSO) failed to provide similar palliative effect. Further analysis revealed that a majority $(61 \%)$ of mice $(n=31)$ that were not diabetic at the initiation of drug treatment (18 weeks of age) remained diabetes-free till the end of the experiment, 34 weeks of age (Figure 1b). However, TSA treatment during the same time interval in a considerable number of overtly diabetic mice $(n=17)$ failed to reverse the full-blown disease (Figure 1c). Overtly diabetic mice lost $>20 \%$ of the body weight within 2 to 4 weeks of diagnosis and therefore killed. Protected mice did not display any abnormality in overall body condition and intake of food and water. At the time of sacrifice, 32 to 36 weeks of age, the body weight of TSA-treated-non-diabetic mice was $25+/-1.5 \mathrm{~g}$ in contrast to $17+/-1.6 \mathrm{~g}$ in diabetic mice. Post-mortem examination of TSA-treated mice revealed no lesion at the site of drug injection or any gross abnormality of major internal organs, such as heart, lung, liver, stomach, intestine, kidney, and spleen.

It was next investigated whether restoration of blood glucose homeostasis was associated with TSA-mediated long-term protection against diabetes. To this end, 32-36 weeks old mice (8-12 weeks after TSA treatment) were given an i.p. challenge of glucose 
following $4 \mathrm{~h}$ of starvation. Data shown in Figure 2a indicate clearance of high blood glucose levels in protected mice with kinetics similar to that of DMSO-treated-nondiabetic and untreated-non-diabetic mice. In contrast, diabetic mice, regardless of treatment, failed to clear excess glucose in the peripheral blood. Consistent with normoglycemia, a sharp increase in insulin level was observed in the blood of TSAtreated-non-diabetic mice within 15 min of glucose challenge (Figure 2b). In contrast, only a meager raise in serum insulin level was observed in TSA-treated-diabetic mice as long as 60 min after glucose challenge. In data not shown, we observed insulin release in response to high glucose challenge in non-diabetic but not in diabetic mice that were either treated with DMSO or left untreated. Thus, prevention of diabetes by TSA treatment is associated with the preservation of the pancreatic $\beta$ cell function. Whereas most intervention strategies are effective at the prediabetic stage ${ }^{14}$, TSA treatment was effective when administered during the period corresponding to the putative transition from peri-insulitis to overt diabetes ${ }^{15}$, indicating the clinical relevance of TSA treatment to intervene diabetes manifestation at a comparatively later stage.

\section{TSA treatment induces histone hyperacetylation}

Since HDAC inhibitors facilitate hyperacetylation of histones and subsequent modification of gene expression ${ }^{2-3}$, we next ascertained whether TSA treatment could increase histone acetylation in the target organ pancreas and in the spleen, which contains $\mathrm{T}$ lymphocytes capable of transferring diabetes into histocompatible, immunodeficient NOD.scid mice. Mice were killed after 2 or 12 weeks of the last injection of TSA given between 18-24 weeks of age and the acidic nuclear extracts from spleens and pancreata were immunoblotted by using antibodies against acetylated $\mathrm{H} 3$ and native $\mathrm{H} 3$ histone. 
Representative data from 3 experiments, each containing 3-5 mice per treatment group, indicate prominent acetylation of histone $\mathrm{H} 3$ in both spleens and pancreata of mice that were treated with TSA 2 weeks earlier (Fig. 3a). Substantial acetylation of H3 was also found in splenocytes and pancreata of 12 weeks old prediabetic mice treated for $24 \mathrm{~h}$ with TSA in vitro. Equivalent loading of nuclear extracts was verified by immunoblotting with an antibody against native $\mathrm{H} 3$. Increases in $\mathrm{H} 3$ acetylation in spleens and pancreata after in vivo and in vitro treatment with TSA were verified by densitometry (Figure 3c). When analyzed 12 weeks after TSA treatment (36 weeks of age), discernible increase in the level of $\mathrm{H} 3$ histone acetylation was not found in both spleens and pancreata regardless of whether they were derived from nondiabetic or diabetic mice (Figure $3 b$ and d). These results indicate that the HDAC inhibitor therapy led to robust histone hyperacetylation in spleens and pancreata of NOD mice shortly after treatment that subsided when long-term protection was stabilized, asserting the anticipated reversible effect of HDAC inhibitors.

\section{Differential effects of TSA on T cell subsets}

The effect of HDAC inhibitor treatment on various $\mathrm{T}$ cell subsets was then determined by flow cytometry. To this end, spleens were obtained from mice when protection was stably established, between 32 and 36 weeks of age. Results shown in Figure $4 \mathrm{a}$ indicate that TSA treatment did not significantly alter the frequency of $\mathrm{CD}^{+}$or $\mathrm{CD} 8^{+}$cells. Interestingly, the frequency of the $\mathrm{CD} 4^{+} \mathrm{CD} 62 \mathrm{~L}^{+}$subset was significantly increased in protected mice (Figure $4 \mathrm{~b}$ ). However, neither $\mathrm{CD} 4^{+} \mathrm{CD} 25^{+}$nor $\mathrm{CD} 4^{+} \mathrm{FoxP}^{+}$ cells were influenced by TSA treatment. These data suggest that the long-term effects of HDAC inhibitor treatment include the upregulation of the $\mathrm{CD} 4^{+} \mathrm{CD} 62 \mathrm{~L}^{+}$cells implicated in the regulation of autoimmune diabetes ${ }^{16}$. Although the frequency of $\mathrm{CD} 4^{+} \mathrm{CD} 25^{+}$and 
$\mathrm{CD}^{+} \mathrm{FoxP}^{+} \mathrm{T}$ regulatory cells did not significantly increase after the stabilization of protection against diabetes (32-36 weeks of age), a transient increase in the numbers and function of these cells shortly after the drug treatment, as observed in other model systems $^{9-10}$, remains a possibility.

\section{TSA treatment reduces inflammation of the islets}

Since cellular inflammation is the primary mechanism of beta cell destruction leading to hyperglycemia, we next ascertained the long-term effects of TSA treatment on the inflammatory response in the pancreata of mice in which protection was stably established, between 32 and 36 weeks of age. Histological examination revealed that the islets of untreated and DMSO-treated diabetic mice had severe inflammation (Grade 3, Figure 5a and c). On the other hand, the islets in the pancreata of TSA-treated and protected mice had substantially less severe cellular infiltration (Figure 5b) and the majority of them displayed no or minimal inflammation (Grade 1). Interestingly, most of the islets from cured mice were smaller and juxtaposed to pancreatic ducts (Figure 5b), consistent with the possible neogeneration of islets. Confocal analysis confirmed the abundance of insulin-positive $\beta$ cells without invasive cellular infiltration in the islets of protected mice (Figure 5b). These data indicate that TSA-mediated amelioration of diabetes is associated with the blockade of progression from peri-insulitis to invasive and destructive insulitis.

\section{Selective upregulation of IFN- $\gamma$ associates with protection against diabetes}

Although alteration of gene expression will be evident shortly (1-2 weeks) after TSA treatment when hyperacetylation of histones was robust (Figure 3a), we wanted to examine whether long-term protection correlates with changes in gene expression. Even 
though HDAC inhibitors have been shown to suppress a number of cytokines in vitro ${ }^{4-8}$, we concentrated only on the cytokines that have been directly implicated in diabetes manifestation such as $I l 4^{17}, I l 17^{18}, I l 18^{19}$, Ifng ${ }^{20-22} \operatorname{Tnfa}^{23}$, and $\operatorname{Inos}^{24}$. Since our preliminary data indicated no significant difference in the expression of intracellular IL10 in splenoctyes of drug treated mice as assessed by flow cytometry, we did not further study $I l 10$ gene expression. Since the role of IL-6 in autoimmune diabetes remains obscure $^{25}$ and IL-12 acts predominantly through IFN- $\gamma^{22}$, these genes were also not investigated. In addition to cytokines, the transcription factors Tbet also known as $T b x 21^{26}, \operatorname{Gata}^{27}$, and $\operatorname{Rorgt}^{28}$, respectively involved in the transcription of Ifng, Il4, and $I l 17$ were also examined. Total RNA was extracted from splenocytes of 32 to 36 weeks old mice (after 8 to 12 weeks of the last injection of TSA) and converted into cDNA and used for gene amplification by real-time quantitative RT-PCR as described ${ }^{29}$. The relative mRNA expression was calculated by the $2^{-\Delta \Delta C}{ }_{\mathrm{T}}$ method ${ }^{29-30}$ using the housekeeping gene, Gapdh as reference. The relative abundance of the steady state levels of Il4, Il17, Ill1, Ifng, Tnfa, Inos, Tbx21, Gata3, and Rorgt mRNA was comparable between unstimulated splenocytes of untreated-diabetic and untreated-non-diabetic mice (Figure 6a). Similarly, the steady state level expression of the cytokine genes and the transcription factors analyzed did not differ between TSA treated diabetic and non-diabetic mice (Figure 6b).

To determine the influence of histone hyperacetylation on the inducible expression of genes in T lymphocytes that are relevant to diabetogenesis, splenocytes were stimulated with PMA and ionomycin that bypass the antigen receptor and engage the downstream signalling pathways or exposed to immobilized anti-CD3 antibody. The data are presented as the fold change in gene expression normalized to the housekeeping 
gene Gapdh and relative to the untreated control, following the $2^{-\Delta \Delta C}{ }_{\mathrm{T}}$ method ${ }^{29-30}$. Substantially higher levels of Ifng mRNA were expressed in splenocytes of TSA-treatednon-diabetic mice in comparison to similarly treated diabetic mice whether they were activated with PMA and ionomycin (Figure 7a) or immobilized anti-CD3 antibody (Figure 7b). In contrast, the expression of other cytokine genes implicated in diabetes, such as Il4, Il17, Il18, Tnfa, and Inos were comparable in spleens of TSA-treated, nondiabetic and diabetic mice. While a majority $(>80 \%)$ of DMSO treated mice routinely develop diabetes, a small fraction of these mice remains free of diabetes. Data shown in Figure 7c indicate that resistance to diabetes in DMSO-treated mice was also associated with increased Ifn expression in activated splenocytes. Similarly, in comparison to untreated-diabetic mice, the inducible expression of Ifng was enhanced in splenocytes of a small number $(\mathrm{n}=3)$ of untreated mice that did not become overtly diabetic during the entire observation period ( 36 weeks of age) (data not shown). Thus, the ability of $\mathrm{T}$ lymphocytes to express Ifng upon stimulation is consistently enhanced in a small number of untreated-non-diabetic mice and in a large number of TSA-treated-non-diabetic mice.

Determination of cytokines by ELISA revealed that the splenocytes of TSAtreated-non-diabetic mice secreted more IFN- $\gamma$ than those of diabetic mice, irrespective of whether they were stimulated with PMA + ionomycin (Figure 8a) or immobilized antiCD3 antibody (Figure 8b). However, the levels of IL-2 or Th2- and Th17-restricted lymphokines respectively, IL-4 and IL-17, and TNF- $\alpha$ produced by splenocytes of diabetic and protected mice were comparable. Taken together, the data indicate that TSAmediated long-term protection against diabetes is associated with increased ability of $\mathrm{T}$ 
lymphocytes to express IFN- $\gamma$ both at the gene and protein levels upon specific stimulation.

\section{Upregulation of Tbet/Tbx21 expression in mice protected from diabetes}

The ability to express Tbet/Tbx21, crucial for IFN- $\gamma$ transactivation ${ }^{26}$ was significantly enhanced in splenocytes of non-diabetic mice that were left untreated or treated with TSA or DMSO. This was seen regardless of whether splenocytes were stimulated with PMA + ionomycin (Figure 9a) or immobilized anti-CD3 antibody (Figure 9b). However, the levels of Gata3 and Rorgt, respectively involved in the transcription of $I l 4$ and $I l l 7^{27-28}$ did not differ between TSA-treated-non-diabetic and -diabetic mice (Figure 9c). Similar data were obtained in untreated and DMSO-treated mice (not shown). Collectively, these data indicate that the attenuation of diabetes manifestation in untreated mice and in those treated with DMSO or TSA is consistently associated with the coordinated upregulation of Ifng and its corresponding transcription factor $T b \times 21$ without influencing other genes implicated in diabetogenesis. 


\section{DISCUSSION}

Our data demonstrate that treatment with the well-characterized HDAC inhibitor TSA can attenuate spontaneous autoimmune diabetes in female NOD mice. This was associated with reduced inflammation of the pancreatic islets, restoration of glucoseinduced insulin release response in $\beta$ cells, and selective increase in a subset of $\mathrm{T}$ regulatory cells. Drug treatment induced histone hyperacetylation and selective enhancement of the inducible expression of Ifng and its transcription factor Tbx21. Thus, epigenetic alterations of the genome may help to reduce the incidence of spontaneous autoimmune diabetes by multiple mechanisms.

Whereas our data demonstrate a strong correlation between the upregulation of IFN- $\gamma$ and resistance against diabetes, previous studies reported conflicting results, primarily owing to the differences inherent to the model systems employed. In acute models of diabetes such as involving cyclophosphamide treatment ${ }^{20-21}$ or adoptive transfer of diabetogenic $\mathrm{T}$ cells $\mathrm{s}^{20,31}$, diabetes was blocked by treatment with neutralizing anti-IFN- $\gamma$ antibodies. On the other hand, ablation of genes encoding IFN- $\gamma$ and its receptor reduced but did not prevent spontaneous diabetes ${ }^{22,32-36}$. Interestingly, injection of recombinant derived IFN- $\gamma$ decreased the incidence of naturally occurring diabetes, accompanied by reduction in IL-12, insulitis and anti-islet effector reactivity ${ }^{37}$. Although IL-12 engaged an IFN- $\gamma$-independent default pathway in IFN- $\gamma$ receptor ablated mice, under normal circumstances, recombinant IL-12 prevented diabetes by IFN- $\gamma$-mediated reduction in pancreatic inflammation and T cell activation ${ }^{22}$. A protective role of IFN- $\gamma$ was also implicated in the attenuation of spontaneous diabetes in NOD mice vaccinated with Bacillus Calmette' Guerin ${ }^{38}$ or injected with Ig-glutamic acid decarboxylase ${ }^{39}$. 
Although neutralization of IFN- $\gamma$ reduced IL-17-producing cells and abolished protection in this model ${ }^{39}$, TSA treatment did not suppress IL-4 or IL-17 both at the mRNA and protein levels. Furthermore, Rorgt and Gata3, transcription factors respectively crucial for $I L 4^{27}$ and $I l 17^{28}$ expression were also not repressed in these mice. Thus, attenuation of naturally occurring diabetes by epigenetic modulation of the genome is associated with upregulation of IFN- $\gamma$-producing T cells and not suppression of Th2 or Th17 cells.

Although IFN- $\gamma$ is predominantly produced by the Th1 subset of CD4 ${ }^{+} \mathrm{T}$-cells, $\mathrm{CD}^{+}$and NK-T cells also produce this lymphokine that can influence both the innate and adaptive immune system. Exogenous administration of IL-12 $2^{22}$ or Bacillus Calmette' Guerin vaccination ${ }^{38}$ increased apoptosis of $\mathrm{CD}^{+}$cells in a manner dependent on IFN- $\gamma$. It will be important to determine whether administration of the neutralizing antibody against IFN- $\gamma$ could abrogate protection against diabetes by suppressing T regulatory population or nullifying deletion of diabetogenic T lymphocytes in TSA-treated mice. Since IFN- $\gamma$ cross-regulates other signal transduction pathways in a number of cell types including islet cells ${ }^{40-41}$, exaggerated IFN- $\gamma$ expression may produce beneficial effects by employing other mechanisms as well.

In addition to Ifng, TSA treatment also upregulated the expression of the transcription factor $T b x 21$. Interestingly, similar coordinated upregulation of these genes was evident in $\mathrm{T}$ lymphocytes of non-diabetic mice that were either treated with the vehicle DMSO or left untreated. We have recently shown that transfusion with allogeneic newborn blood protected NOD mice from spontaneous diabetes associated with increased expression of $T b \times 21^{29}$. Since $T b \times 21$ is required not only for the transcription of $I f n g^{26}$ but also for a number of immune functions including priming of $\mathrm{T}$ cells by dendritic cells and 
expression of CD122 and CxCR $3^{42-43}$, upregulation of $T b \times 21$ may provide protection against diabetes via multiple mechanisms. It is interesting to note that the deletion of Tbx21 in both the innate and adaptive immune system prevented the development of diabetes in NOD mice ${ }^{44}$. In contrast, Tbx21 deletion did not prevent insulitis in Balb/c mice ${ }^{45}$, suggesting that insulitis, an obligate component of autoimmune diabetes is not influenced by $T b \times 21$ deletion. Since a number of immune functions require $T b \times 21^{26,42-43}$, further work is necessary to delineate the mechanisms by which $T b \times 21$ contributes to protection against autoimmune diabetes. Histone acetylation marks have been revealed at the Ifng locus of poralized Th1 cells driven to produce IFN- $\gamma$, distinct from those found in IL-4-producing Th2 cells by chromatin immunoprecipitation ${ }^{46}$. Similar studies may unravel unique histone marks at the Ifng and Tbet loci of $\mathrm{CD}^{+} \mathrm{T}$ lymphocytes implicated in diabetes ${ }^{47}$. These data will also shed light on the epigenetic memory that renders female NOD mice highly susceptible to diabetes and how TSA treatment can erase this epigenetic memory resulting in the cure of the disease.

Induction of Ifng and Tbx21 but not seven other genes tested was upregulated in T cells derived from TSA-treated mice that were protected from diabetes. Since the role of IL- $6^{25}$ in autoimmune diabetes remains unclear, it was not examined whether TSA treatment could alter its expression. It is well documented that IL-2 has dual roles in immune responses. In addition to promoting the proliferation and differentiation of Tcells, B-cells and NK cells, IL-2 is also essential for the development, homeostasis and function of $\mathrm{CD}^{+} \mathrm{CD} 25^{+} \mathrm{FoxP}^{+}{ }^{+}$regulatory cells, which in turn control the immune responses including autoimmune pathologies ${ }^{48}$. Engineered haplodeficiency of $I l 2$ gene expression reduced IL-2 production by twofold, diminished the function of $\mathrm{CD} 4{ }^{+} \mathrm{CD} 25^{+}$ 
$\mathrm{T}$ regulatory cells and exacerbated diabetes ${ }^{48}$. However, protection against diabetes induced by TSA treatment in wild type NOD mice was not associated with dramatic alteration in the secretion of IL-2 by T lymphocytes or the frequency of IL-2-dependent $\mathrm{CD} 4^{+} \mathrm{CD} 25^{+} \mathrm{FoxP}^{+} \mathrm{T}$ regulatory cells. Thus, amelioration of diabetes by chromatin remodeling does not appear to be due to IL-2 mediated effects on the immune system including the $\mathrm{CD} 4^{+} \mathrm{CD} 25^{+} \mathrm{FoxP}^{+}$subset of $\mathrm{T}$ regulatory cells.

Our data showing selective upregulation of Ifng are consistent with the notion that the alteration of the 'histone code' is a powerful way of modulating a small set of inducible genes (2-20\%) in a tissue-specific and context-dependent manner ${ }^{2-3}$. Importantly, we also observed an association between the coordinated upregulation of Ifng and Tbx21 and resistance to diabetes in a small number of untreated and DMSOtreated mice. This unexpected and surprising finding suggests that protection against diabetes and enhanced ability of T lymphocytes to express Ifng and $T b \times 21$ in response to $\mathrm{T}$ cell receptor-mediated activation may be causatively linked. Further, this intriguing finding suggests that erasing the epigenetic memory by TSA treatment may facilitate the expression of the gene profile similar to that of naturally protected mice. Since all of the untreated mice develop peri-insulitis and only some of them will never progress to become overtly diabetic, mechanisms must exist in these mice to retard full-blown diabetes. Epigenetic modulation appears to amplify these mechanisms leading to the blockade of overt diabetes in a large proportion of diabetes-prone mice. While exaggeration of Ifng and Tbx21 may play a pivotal role, regulation of other genes at earlier time points may also contribute to protection against diabetes due to epigenetic changes of the genome. Further work is necessary to address this issue. 
Treatment with TSA induced prominent hypercetylation of $\mathrm{H} 3$ histone in splenocytes shortly after treatment (1-2 weeks), as observed in other models ${ }^{11,13}$. In addition to the spleen, histone acetylation was also found in the target organ pancreas, which may lead to altered gene expression. Epigenetic changes of the pancreas are likely to complement the epigenetic changes in $\mathrm{T}$ lymphocytes to bring about protection against diabetes. When protection was fully stabilized (32-36 weeks of age), H3 acetylation detected by western blotting was undetectable, indicating the anticipated reversible nature of histone acetylation ${ }^{1-3}$. This indicates that the disease intervention is largely dependent on events that occur during the treatment period (18-24 weeks of age). Although this period corresponds to check point 2 , thought to include a second wave of immune response culminating in full-blown diabetes ${ }^{15}$, some mice proceeded to become diabetic even after continuous drug treatment. Whereas weekly administration of TSA (500 $\mu \mathrm{g} / \mathrm{kg}$ body weight) failed to reverse the end stage disease in a large number of mice, treatment with a comparable dose ( $8 \mu \mathrm{g}$ per $\sim 20 \mathrm{~g}$ mouse equals to $400 \mu \mathrm{g} / \mathrm{Kg}$ body weight) of FR901228 twice a week for 8 weeks was shown to reverse overt diabetes in a very small number ( $n=3$ ) of NOD mice ${ }^{7}$. Whereas the cyclic tetrapeptide FR901228 inhibits only the class I HDACs, the hydroxamic acid TSA is the most potent inhibitor of class I, II and IV HDACs $^{2}$. Although the differences in the selectivity of the HDAC inhibitors cannot explain the discrepancy between these results, it is possible that more frequent injections of FR901228 may curtail the ongoing inflammatory response better than weekly injections with TSA. Nevertheless, it is important to recognize the major obstacles in reversing the end stage diabetes. By the time diabetes is diagnosed, $>80 \%$ of islets are already destroyed and the remaining $\beta$-cells are under severe attack by inflammatory 
responses. Any intervention strategy should not only curtail the ongoing autoimmune attack on $\beta$-cells effectively but also facilitate the replenishment of islets to restore normoglycemia rapidly. Our data are congruent with the necessity of intervention preferably during the transition from prediabetic to diabetic stage, 18-24 weeks of age, in most female NOD mice. This time frame is adequate to quell the damage caused by autoimmune attack and allow the replenishment of islets. However, the transition from prediabetes to overt diabetes may not occur synchronously as evidenced by the occurrence of overt diabetes in a small fraction of mice that were $<18$ weeks old. Heterogeneity in response to HDAC inhibitor treatment may explain why some mice succumb to diabetes even when the drug treatment began at 18 weeks of age and continued for another 6 weeks. It is possible that earlier therapeutic intervention $(<18$ weeks of age) may provide benefit to those mice that become overtly diabetic much earlier than most NOD mice. Nevertheless, the observation that TSA can prevent the transition from insulitis to overt diabetes in a majority of mice has clinical relevance since most intervention therapies reported so far are effective at the prediabetic period but not at an advanced stage of the disease ${ }^{14}$.

In addition to histones, HDAC inhibitors can also facilitate acetylation of more than 50 transcription factors ${ }^{2-3}$. Treatment of mice with higher concentrations of TSA than used in our studies resulted in FoxP3 acetylation and upregulation of $\mathrm{CD}^{+} \mathrm{FoxP}^{+} \mathrm{T}$ regulatory cell number and function ${ }^{9-10}$. In contrast, only the frequency of $\mathrm{CD}^{+} \mathrm{CD} 6 \mathrm{~L}^{+}$ but not $\mathrm{CD} 4{ }^{+} \mathrm{FoxP}^{+} \mathrm{T}$ regulatory cells was increased when analyzed 8 to 12 weeks after the last injection of TSA in contrast to typically 1-2 weeks after drug treatment in other reports. Although we analyzed the frequency of the T regulatory cells in the spleen as 
most previous studies, it will be more informative to examine the changes in the numbers and function of the $\mathrm{T}$ regulatory cells present in the pancreatic lymph nodes and in the target organ pancreas of TSA treated mice. Since the $\mathrm{CD} 4{ }^{+} \mathrm{CD} 62 \mathrm{~L}^{+}$but not $\mathrm{CD} 4{ }^{+} \mathrm{CD} 25^{+}$ $\mathrm{T}$ regulatory cells had been shown to protect mice from autoimmune diabetes ${ }^{16}$, our data indicating a specific increase in $\mathrm{CD} 4^{+} \mathrm{CD} 62 \mathrm{~L}^{+}$cells by epigenetic modulation may have implications for the treatment of diabetes. Since most of the islets in cured mice appeared smaller and juxtaposed to pancreatic ducts, it is possible that TSA treatment can facilitate the neogeneration of islets in vivo as observed in fetal islets in vitro ${ }^{49}$. Thus, treatment with HDAC inhibitors may provide protection against spontaneous autoimmune diabetes by multiple mechanisms. A thorough understanding of these mechanisms is a prerequisite for the application of this novel approach to treat patients with type 1 diabetes. Although genetic and environmental factors have been implicated in the manifestation of autoimmune diabetes, our data indicate that epigenetics is involved in fine-tuning of the immune system to deviate the autoimmune process. 


\section{METHODS}

\section{Mice}

Female NOD/Ltj $\left(\mathrm{H}-2^{\mathrm{g} 7}\right)$ mice were purchased from The Jackson Laboratories (Bar Harbor, ME). The University of Illinois at Chicago approved the animal protocol. Experiments were conducted according to the Animal Welfare Act and the National Institutes of Health guidelines for the care and use of animals in biomedical research.

\section{Treatment of mice and diabetes monitoring}

A stock solution of TSA (Biomol International, Plymouth Meeting, PA) was prepared at $1 \mathrm{mg} / \mathrm{ml}$ concentration in DMSO and stored at $-20^{\circ} \mathrm{C}$. TSA or equivalent amount of DMSO was diluted in phosphate buffered saline and injected s.c. into female NOD/Ltj mice at weekly intervals. Tail vein blood was tested weekly for glucose levels using a glucometer and $>250 \mathrm{mg} / \mathrm{dL}$ of glucose were considered diabetic ${ }^{29}$. For glucose tolerance test, food was withdrawn for $4 \mathrm{~h}$ before an i.p. injection of dextrose $(2 \mathrm{~g} / \mathrm{kg}$ body weight) and blood glucose levels were tested at different time intervals as described $^{29}$. Insulin levels in the sera were measured using an Ultra Sensitive Mouse Insulin ELISA kit obtained from Crystal Chem (Downers Grove, IL, range: 0.1-12.8 $\mathrm{ng} / \mathrm{ml})$.

\section{Flow cytometry}

Splenocytes were stained with FITC-coupled anti-CD4, PE-conjugated anti-CD8, or a combination of PE-conjugated anti-CD4 and FITC-labeled anti-CD25 (eBioscience, San Diego, CA) and analyzed by flow cytometry as described ${ }^{29}$. Intracellular FoxP3 staining was performed using a kit from eBioscience. Briefly, splenocytes were stained 
with CD4-FITC, permeabilized and stained with PE-conjugated anti-FoxP3 antibody.

Values were subtracted from those stained with isotype matched PE-conjugated antibody.

\section{Assessment of gene expression by real-time RT-PCR}

Splenocytes $\left(5 \times 10^{6} / \mathrm{ml}\right)$ from individual mice were stimulated with $100 \mathrm{ng}$ of phorbol 12-myristate 13-acetate (PMA) and $1 \mu \mathrm{g}$ of ionomycin (Sigma-Aldrich, St. Louis, MO) or cultured in tissue culture plates previously coated with $5 \mu \mathrm{g} / \mathrm{ml}$ of antiCD3 antibody (2C11, eBioscience, San Diego, CA) in complete RPMI 1640 medium (Invitrogen, Carlsbad, CA) supplemented with antibiotics and 10\% $\mathrm{FBS}^{29,50}$. After overnight culture, splenocytes from 3 to 5 mice from the same experimental group were pooled and lysed in TRIzol (Invitrogen). Total RNA was isolated, treated with DNase and reverse transcribed to cDNA using High-Capacity cDNA Reverse Transcription kit (Applied Biosytems, Carlsbad, CA). Real-time quantitative RT-PCR was performed on an ABI Prism 7500 Real-Time PCR system (Applied Biosystems) using $1 \mu 1$ of cDNA equivalent to 100 ng of RNA and 2X SYBR Premix Ex Taq (Perfect Real Time) reagent (Takara-Clontech, Mountain View, CA). Primer sets for mouse Gapdh, Il4, Il17, Ill8, Ifng, Tnfa, Inos, Tbet/Tbx21, Gata3, and Rorgt were designed as described ${ }^{29}$ and synthesized at Integrated DNA Technologies (Coralville, IA). Sizes of amplicons and the absence of primer-dimer were verified by electrophoresis of PCR products as described ${ }^{29}$. Each sample was analyzed in triplicate. Since normalized $\mathrm{C}_{\mathrm{T}}$ values are not recommended for statistical evaluation ${ }^{30}$, the level of expression of any given gene in each sample was determined using the endogenous reference gene Gapdh as the normalizer using the $2^{-\Delta \Delta C}{ }_{\mathrm{T}}$ method ${ }^{29-30}$. Differences in the expression of genes 
between unstimulated and stimulated cultures were calculated as the fold change in gene expression normalized to Gapdh and relative to the untreated control, using the $2^{-}$ ${ }_{\mathrm{T}}^{\Delta \Delta C}$ method ${ }^{29-30}$. Statistical significance was calculated only between the groups that were analyzed simultaneously.

\section{ELISA}

Culture supernatant collected after overnight incubation of splenocytes was assessed for cytokine levels using commercially available ELISA kits (eBioscience).

\section{Immunoblotting}

Acidic nuclear extracts were prepared from spleens and pancreata of untreated and TSA-treated mice as described ${ }^{6}$. As positive controls, extracts were also prepared from splenocytes $\left(5 \times 10^{6}\right.$ cells) and small pieces $(1-2 \mathrm{~cm})$ of pancreata obtained from prediabetic (12 weeks old) female NOD mice after overnight activation with $100 \mathrm{ng}$ of $\mathrm{TSA} / \mathrm{ml}$ of media. Proteins $(10 \mu \mathrm{g})$ were separated on a SDS-PAGE gel, transferred onto a polyvinylidene fluoride membrane and probed with rabbit polyclonal pan specific antihistone $\mathrm{H} 3$ and anti-acetyl histone $\mathrm{H} 3$ antibodies separately (Upstate Biotech, Billerica, MA). After incubation with horseradish peroxidase conjugated anti-rabbit antibody, proteins were visualized using ECL plus (GE Healthcare, Piscataway, NJ). The integrated density of bands were measured using the ImageJ $1.34 \mathrm{~s}$ software. The integrated density of acetylated $\mathrm{H} 3$ was divided by that of total $\mathrm{H} 3$ to obtain the fold change in acetylation of $\mathrm{H} 3$ in individual samples. 


\section{Histology and confocal microscopy}

Formalin fixed pancreatic sections were stained with $\mathrm{H} \& \mathrm{E}$ and at least 3 sections per pancreas were analyzed by light microscopy and a score was assigned as follows ${ }^{29}: 1$, No to mild peri-insulitis, 2, Moderate infiltration $(<50 \%)$ and 3, Severe $(>50 \%)$ and destructive infiltration. Sections were stained with 1:100 diluted guinea pig anti-insulin antiserum (Zymed Laboratories, South San Francisco, CA) followed by 1:1000 diluted

tetramethyl rhodamine iso-thiocyanate labeled rabbit-anti-guinea pig Ig (Sigma-Aldrich). Nuclei were counterstained with Hoechst and confocal images were acquired on a Zeiss LSM510 laser-scanning microscope and processed using the Zeiss LSM Image browser (4.0 version, Zeiss, Oberkochen, Germany).

\section{Statistics}

Statistical analysis was performed using an unpaired two-tailed Student's $t$ test (GraphPad Prism, San Diego, CA).

\section{ACKNOWLEDGEMENT}

Venkat Kotireddy is acknowledged for technical help. This work was supported by the Department of Surgery and the Department of Medicine, University of Illinois at Chicago. 


\section{REFERENCES}

1 Jenuwein T, Allis CD. Translating the histone code. Science 2002; 293:1074-80.

2 Marks PA, Richon VM, Breslow R, Rifkind RA. Histone deacetylase inhibitors as new cancer drugs. Curr. Opin. Oncol. 2001; 13: 477-83.

3 Van Lint C, Emiliani S, Verdin E. The expression of a small fraction of cellular genes is changed in response to histone hyeracetylation. Gene Expr. 1996; 5: 24553.

4 Moreira JM, Scheipers P, Sorensen P. The histone deacetylase inhibitor Trichostatin A modulates CD4+ T cell responses. BMC Cancer 2003; 3: 30.

5 Takahashi I, Miyaji H, Yoshida T, Sato S, Mizukami T. Selective inhibition of IL2 gene expression by trichostatin A, a potent inhibitor of mammalian histone deacetylase. J. Antibiot. 1996; 49: 453-57.

6 Mishra N, Reilly CM, Brown DR, Ruiz P, Gilkeson GS. Histone deacetylase inhibitors modulate renal disease in the MRL-lpr/lpr mouse. J. Clin. Invest. 2003; 111: 539-52.

7 Skov S, Rieneck K, Bovin LF, Skark K, Tomra S, Michelsen BK et al. Histone deacetylase inhibitors: a new class of immunosuppressors targeting a novel signal pathway essential for CD154 expression. Blood 2003; 101: 1430-38.

8 Mishra N, Brown DR, Olorenshaw IM, Kammer GM. Trichostatin A reverses skewed expression of CD154, interleukin-10, and interferon-gamma gene and 
protein expression in lupus T cells. Proc. Natl. Acad. Sci. USA 2001; 98: 262833.

9 Tao R, de Zoeten EF, Ozkaynak E, Chen C, Wang L, Porrett PM et al. Deacetylase inhibition promotes the generation and function of regulatory $\mathrm{T}$ cells. Nat. Med. 2007; 13: 1299-07.

10 Reilly CM, Thomas M, Gogal Jr R, Olgun S, Santo A, Sodhi R et al. The histone deacetylase inhibitor trichostatin A upregulates regulatory $\mathrm{T}$ cells and modulates autoimmunity in NZB/W F1 mice. J. Autoimmun. 2008; 31: 123-30.

11 Glauben R, Batra A, Fedke I, Zeitz M, Lehr HA, Leoni F et al. Histone hyperacetylation is associated with amelioration of experimental colitis in mice. J. Immunol. 2006; 176: 5015-22.

12 Choi J-H, Oh S-W, Kang M-S, Kwon H. J, Oh G-T, Kim D-Y. Trichostatin A attenuates airway inflammation in mouse asthma model. Clin. Exp. Allergy 2005; 35: 89-96.

13 Camelo S, Iglesias AH, Hwang D, Due B, Ryu H, Smith K et al. Transcriptional therapy with the histone deacetylase inhibitor trichostatin A ameliorates experimental autoimmune encephalomyelitis. J. Neuroimmunol. 2005; 164: 1021.

14 Shoda LK, Young DL, Ramanujan S, Whiting CC, Atkinson MA, Bluestone JA et al. A comprehensive review of interventions in the NOD mouse and implications for translation. Immunity 2005; 23: 115-26.

15 André I, Gonzalez A, Wang B, Katz J, Benoist C, Mathis D. Checkpoints in the 
progression of autoimmune disease: lessons from diabetes models. Proc. Natl. Acad. Sci. U S A 1996; 93: 2260-63.

16 Alyanakian MA, You S, Damotte D, Gouarin C, Esling A, Garcia C, et al. Diversity of regulatory CD4+T cells controlling distinct organ-specific autoimmune diseases. Proc. Natl. Acad. Sci. U S A. 2003; 100:15806-11.

17. Anderson JT, Cornelius JG, Jarpe AJ, Winter WE, Peck AB. Insulin-dependent diabetes in the NOD mouse model. II. Beta cell destruction in autoimmune diabetes is a TH2 and not a TH1 mediated event. Autoimmunity 1993; 15:113-22.

18 Emamaullee JA, Davis J, Merani S, Toso C, Elliott JF, Thiesen A et al. Inhibition of Th17 cells regulates autoimmune diabetes in NOD mice. Diabetes 2009; 58 : $1302-11$.

19 Oikawa Y, Shimada A, Kasuga A, Morimoto J, Osaki T, Tahara H et al. Systemic administration of IL-18 promotes diabetes development in young nonobese diabetic mice. J. Immunol. 2003; 171: 5865-75.

20 Debray-Sachs M, Carnaud C, Boitard C, Cohen H, Gresser I, Bedossa P et al. Prevention of diabetes in NOD mice treated with antibody to murine IFN gamma. J. Autoimmun. 1991; 4: 237-48.

21 Campbell IL, Kay TW, Oxbrow L, Harrison LC. Essential role for interferongamma and interleukin-6 in autoimmune insulin-dependent diabetes in NOD/Wehi mice. J. Clin. Invest. 1991; 87: 739-42.

22 Trembleau S, Penna G, Gregori S, Giarratana N, Adorini L. IL-12 administration accelerates autoimmune diabetes in both wild-type and IFN-gamma-deficient 
nonobese diabetic mice, revealing pathogenic and protective effects of IL-12induced IFN-gamma. J. Immunol. 2003; 170: 5491-01.

23 Yang XD, Tisch R, Singer SM, Cao ZA, Liblau RS, Schreiber RD et al. Effect of tumor necrosis factor alpha on insulin-dependent diabetes mellitus in NOD mice. I. The early development of autoimmunity and the diabetogenic process. J. Exp. Med. 1994; 180: 995-04.

24 Yasuda H, Jin Z, Nakayama M, Yamada K, Kishi M, Okumachi Y et al. NOmediated cytotoxicity contributes to multiple low-dose streptozotocin-induced diabetes but not to NOD diabetes. Diabetes Res. Clin. Pract. 2009; 83: 200-07.

25 Kristiansen OP, Mandrup-Poulsen T. Interleukin-6 and diabetes: the good, the bad, or the indifferent? Diabetes 2005; 54: S114-24.

26 Szabo SJ, Sullivan BM, Stemmann C, Satoskar AR, Sleckman BP, Glimcher LH. Distinct effects of T-bet in $\mathrm{T}_{\mathrm{H}} 1$ lineage commitment and IFN-gamma production in CD4 and CD8 T cells. Science 2001; 295: 338-42.

27 Yu Q, Sharma A, Oh, SY, Moon HG, Hossain MZ, Salay TM et al. T cell factor 1 initiates the $\mathrm{T}$ helper type 2 fate by inducing the transcription factor GATA-3 and repressing interferon-gamma. Nat. Immunol. 2009; 10: 992-99.

28 Ivanov II, McKenzie BS, Zhou L, Tadokoro CE, Lepelley A, Lafaille JJ et al. The orphan nuclear receptor RORgammat directs the differentiation program of proinflammatory IL-17+ T helper cells. Cell 2006; 126: 1121-33.

29 Jayaraman S, Patel T, Patel V, Ajani S, Garza R, Jayaraman A et al. Transfusion of NOD mice with allogeneic newborn blood ameliorates autoimmune diabetes 
and modifies the expression of selected immune response genes. J. Immunol. 2010; 184: 3008-15.

30 Livak KJ, Schmittgen TD. Analysis of relative gene expression data using realtime quantitative PCR and the 2(-Delta Delta C(T)) method. Methods 2001; 25: 402-08.

31 Calderon B, Suri A, Pan XO, Mills JC, Unanue ER. IFN-gamma-dependent regulatory circuits in immune inflammation highlighted in diabetes. J. Immunol. 2008; 181: 6964-74.

32 Hultgren B, Huang X, Dybdal N, Stewart TA. Genetic absence of gammainterferon delays but does not prevent diabetes in NOD mice. Diabetes 1996; 45: $812-17$.

33 Nicoletti F, Zaccone P, Di Marco R, Di Mauro M, Magro G, Grasso S et al. The effects of a nonimmunogenic form of murine soluble interferon-gamma receptor on the development of autoimmune diabetes in the NOD mouse. Endocrinology 1996; 137: 5567-75.

34 Wang B, Andre I, Gonzalez A, Katz JD, Aguet M, Benoist C et al. Interferongamma impacts at multiple points during the progression of autoimmune diabetes. Proc. Natl. Acad. Sci. USA 1997; 94: 13844-49.

35 Serreze DV, Post CM, Chapman HD, Johnson EA, Lu B, Rothman PB. Interferon-gamma receptor signaling is dispensable in the development of type 1 diabetes in NOD mice. Diabetes 2000; 49: 2007-11. 
36 Kanagawa O, Xu G, Tevaarwerk A, Vaupel BA. Protection of nonobese diabetic mice from diabetes by gene(s) closely linked to IFN-gamma receptor loci. J. Immunol. 2000; 164: 3919-23.

37 Sobel DO, Han J, Williams J, Yoon JW, Jun HS, Ahvazi B. Gamma interferon paradoxically inhibits the development of diabetes in the NOD mouse. J. Autoimmun. 2002; 19: 129-37.

38 Qin H-Y, Chaturvedi P, Singh B. In vivo apoptosis of diabetogenic T cells in NOD mice by IFN-gamma/TNF-alpha. Int. Immunol. 2004; 16: 1723-32.

39 Jain R, Tartar DM, Gregg RK, Divekar RD, Bell JJ, Lee HH et al. Innocuous IFNgamma induced by adjuvant-free antigen restores normoglycemia in NOD mice through inhibition of IL-17 production. J. Exp. Med. 2008; 205: 207-18.

40 Gysemans C, Callewaert H, Overbergh L, Mathieu C. Cytokine signaling in the beta-cell: a dual role for IFNgamma. Biochem. Soc. Trans. 2008; 36: 328-33.

$41 \mathrm{Hu} \mathrm{X}$, Ivashkiv LB. Cross-regulation of signaling pathways by interferongamma:Implications for immune responses and autoimmune diseases. Immunity 2009; 31: 539-50.

42 Lugo-Villarino G, Maldonado-Lopez R, Possemato R, Penaranda C, Glimcher LH. T-bet is required for optimal production of IFN-gamma and antigen-specific T cell activation by dendritic cells. Proc. Natl. Acad. Sci. U S A 2003; 100: 774954.

43 Matsuda JL, George TC, Hagman J, Gapin L. Temporal dissection of T-bet functions. J. Immunol. 2007; 178: 3457-65. 
44 Esensten JH, Lee MR, Glimcher LH, Bluestone JA. T-bet-deficient NOD mice are protected from diabetes due to defects in both $\mathrm{T}$ cell and innate immune system function. J. Immunol. 2009; 183:75-82 .

45 Melanitou E, Liu E, Miao D, Yu L, Glimcher LH, Eisenbarth G. Absence of the T-bet gene coding for the Th1-related transcription factor does not affect diabetesassociated phenotypes in Balb/c mice. Ann. N. Y. Acad. Sci. 2003; 1005: 187-91.

46 Placek K, Coffre M, Maiella S, Bianchi E, Rogge L. Genetic and epigenetic networks controlling T helper 1 cell differentiation. Immunology 2009; 127: 15562.

47 Christianson SW, Shultz LD, Leiter EH. Adoptive transfer of diabetes into immunodeficient NOD-scid/scid mice. Relative contributions of CD4+ and CD8+ T-cells from diabetic versus prediabetic NOD.NON-Thy-1a donors. Diabetes 1993; 42: 44-55.

48 Wang J, Wicker LS, Santamaria P. IL-2 and its high-affinity receptor: genetic control of immunoregulation and autoimmunity. Semin. Immunol. 2009; 21: 36371.

49 Haumaitre C, Lenoir O, Scharfmann R. Histone deacetylase inhibitors modify pancreatic cell fate determination and amplify endocrine progenitors. Mol. Cell. Biol. 2008; 28: 6373-83.

50 Jayaraman S, Luo Y, Dorf ME. Tolerance induction in T helper (Th1) cells by thymic macrophages. J. Immunol. 1992; 148: 2672-81. 


\section{FIGURE LEGENDS}

\section{Figure 1. Amelioration of diabetes by TSA treatment.}

(a). Female NOD mice were injected s.c. with TSA or DMSO and blood glucose levels monitored weekly. Mice were considered diabetic when blood glucose levels reached $>250 \mathrm{mg} / \mathrm{dL}$. Numbers of mice tested per group are shown in parentheses. The statistical significance between untreated and those injected with TSA between 18-24 weeks (wk) is indicated. (b). Mice treated with TSA between 18-24 weeks were further analyzed. Mice that were non-diabetic at the beginning of drug treatment were followed for diabetes incidence. Blood glucose levels of individual mice that became diabetic during the course of treatment and those remained non-diabetic are shown. (c). Blood glucose levels of overtly diabetic mice at the initiation of TSA treatment (18 weeks) are shown. All of these mice received weekly injections of TSA till 24 weeks of age unless mice died of overt diabetes.

\section{Figure 2. Normoglycemia in protected mice.}

(a). Mice were left untreated or treated with TSA or DMSO between 18-24 weeks of age and challenged with glucose when they reached 32 to 36 weeks of age. Blood glucose levels in different groups of mice are shown (mean +/- SD). Numbers of mice are shown in parentheses (b). Insulin levels (mean +/-SD) in TSA-treated-non-diabetic and TSAtreated-diabetic mice challenged with high levels of glucose are shown.

\section{Figure 3. Transient H3 histone acetylation by TSA treatment.}

(a). Mice were killed 2 weeks after the last injection of TSA given between 18 and 24 weeks of age. Representative data from 3 independent experiments are shown. In each 
experiment, spleens and pancreata were harvested and pooled from 3-5 mice per treatment group and acidic nuclear extracts derived from them were immunoblotted with antibodies against acetylated and native $\mathrm{H} 3$ histone. Splenocytes and pancreata were also obtained from 12 weeks old 3 prediabetic mice, pooled and treated overnight with TSA in vitro. (b). Acetylation of $\mathrm{H} 3$ histone was analyzed in tissues obtained from 36 weeks old mice that received the last injection of TSA 12 weeks earlier. Splenocytes and pancreata were obtained from 3-5 mice per group in each experiment and the data were shown from a representative of two different experiments. (c) The intensity of the individual bands shown in (a) was determined using the ImageJ software. Fold change in $\mathrm{H} 3$ acetylation was calculated by dividing the intensity of acetylated $\mathrm{H} 3$ by total $\mathrm{H} 3$ levels in each sample. Shown is the mean $+/$ - standard deviation. The levels of significance between groups are also indicated. (d). The fold change in $\mathrm{H} 3$ histone acetylation in samples shown in (b) is indicated and the differences between groups were not significant.

\section{Figure 4. Increase in a subset of T regulatory cells by TSA treatment.}

(a). The frequency of $\mathrm{CD} 4^{+}$and $\mathrm{CD} 8^{+}$cells in splenocytes of diabetic mice $(\mathrm{n}=17)$ and those treated with TSA between 18 and 24 weeks of age and remained diabetes free $(\mathrm{n}=17)$ is shown. Mice were killed between 32-36 weeks of age and splenocytes were analyzed by flow cytometry. Shown is mean $+/$ - SD. (b). Splenocytes from untreateddiabetic $(\mathrm{n}=12)$ and TSA-treated, non-diabetic mice $(\mathrm{n}=7)$ were also analyzed between 32 and 36 wks of age by flow cytometry. The frequency of indicated subsets in splenocytes is shown as mean $+/-\mathrm{SD}$. The statistical significance between groups is shown. 


\section{Figure 5. Reduced insulitis in pancreata of TSA treated mice.}

Histological sections of pancreata obtained from diabetic (a) and TSA-treated-nondiabetic mice (b) were stained with H \& E (upper panels, x200 magnification). Lower panels represent confocal images of pancreatic sections stained with an antibody to insulin (red) and Hoechst to visualize nuclei (blue). Bar size $=20 \mu \mathrm{M}$. (c). Pancreatic sections were scored for cellular infiltration as follows: 1, no or little infiltration; 2. periinsulitis; and 3. heavy and invasive cellular infiltration. A total of 45-48 islets were scored from 8 to 15 mice per group.

\section{Figure 6. Steady state levels of gene expression.}

Splenocytes from diabetic and non-diabetic mice that were untreated (a) or treated with TSA (b) were analyzed for the steady state levels of gene expression by real-time RTPCR. Relative mRNA abundance was analyzed simultaneously in diabetic and nondiabetic mice from untreated mice and those treated with TSA. The expression level of the gene of interest was normalized against Gapdh individually and determined by using the $2^{-\Delta \Delta C}{ }_{T}$ method ${ }^{30}$. Data shown are mean $+/-$ SD of triplicate determinations from samples pooled from 3 to 5 mice per group. The experiment was repeated 3 to 5 times with separate pools of samples with similar results. The differences in gene expression between diabetic and non-diabetic mice were not statistically different.

\section{Figure 7. Modulation of gene expression in splenocytes of TSA-treated mice.}

Spleens were harvested from 28 to 36 weeks old mice that were treated with TSA during 18-24 weeks of age. Splenocytes were cultured in media alone or with PMA + ionomycin (a). Cells were also incubated in plates coated with anti-CD3 antibody (b). Spleen cells 
from DMSO-treated mice were incubated with PMA + ionomycin (c). Expression of each gene was calculated in cells cultured in media (control) alone and after specific stimulation. The fold change in specific mRNA expression was calculated by comparing the relative gene expression normalized to Gapdh in control and stimulated samples using the $2^{-\Delta \Delta C}{ }_{\mathrm{T}}$ method $^{30}$. Data shown are mean $+/-\mathrm{SD}$ of triplicate determinations from samples pooled from 3 to 5 mice per group and the experiment was repeated 3 to 5 times with similar results. Only the Ifng mRNA expression between diabetic and non-diabetic mice regardless of treatment was statistically significant.

\section{Figure 8. Upregulation of IFN- $\gamma$ secretion by TSA treatment.}

Splenocytes from diabetic mice and TSA-treated-non-diabetic mice were stimulated with PMA + ionomycin (a) or immobilized anti-CD3 antibody (b). Controls were cultured in media alone. After overnight culture, supernatant was collected and assayed for the levels of indicated cytokines by ELISA. Data shown are mean +/- SD of duplicate samples pooled from 2-3 experiments. Each experiment contained spleens from 3-5 mice per group. Data shown are those obtained in stimulated cultures subtracted from media controls. Only the amounts of IFN- $\gamma$ between control and TSA-treated mice were statistically different.

\section{Figure 9. Upregulation of $T b x 21$ but not Gata3 or Rorgt in non-diabetic mice regardless of treatment.}

Diabetic and non-diabetic mice from untreated, DMSO-treated and TSA-treated mice were killed at 22 to 36 weeks of age. Splenocytes were stimulated either with PMA + ionomycin (a) or immobilized anti-CD3 antibody (b). The increase in the expression of $T b \times 21$ gene in activated and unstimulated cells from each group was normalized to the 
endogenous reference Gapdh and determined using the $2^{-\Delta \Delta C}{ }_{\mathrm{T}}$ method $^{30}$. The bars indicate the increase in the expression of $T b \times 21$ in stimulated cells compared to those incubated with media alone. The statistical differences between diabetic and non-diabetic mice are indicated. Inducible expression of Gata3 and Rorgt was also analyzed in splenocytes of TSA-treated-diabetic and drug treated-non-diabetic mice after activation with PMA + ionnomycin (c). The differences in the expression of genes between the groups were not significant. Representative data from 3 experiments, each with 3 to 5 mice are shown. Each bar represents mean +/- SD of triplicate determinations per sample. 
Fig. 1

a

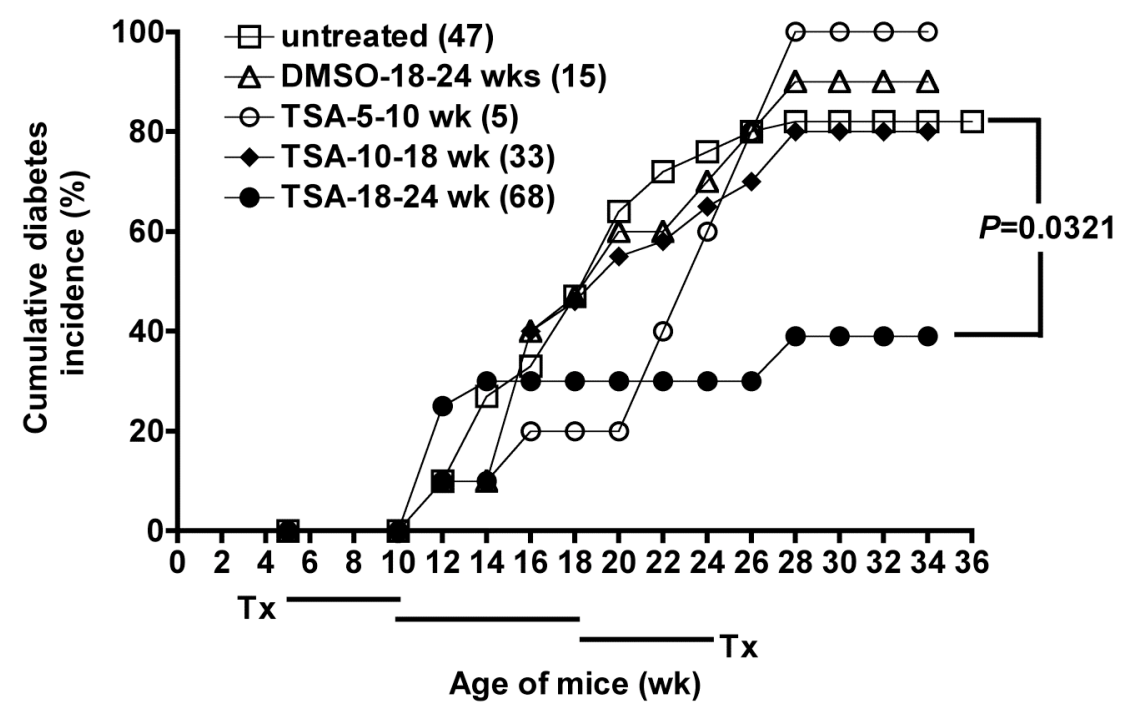

b

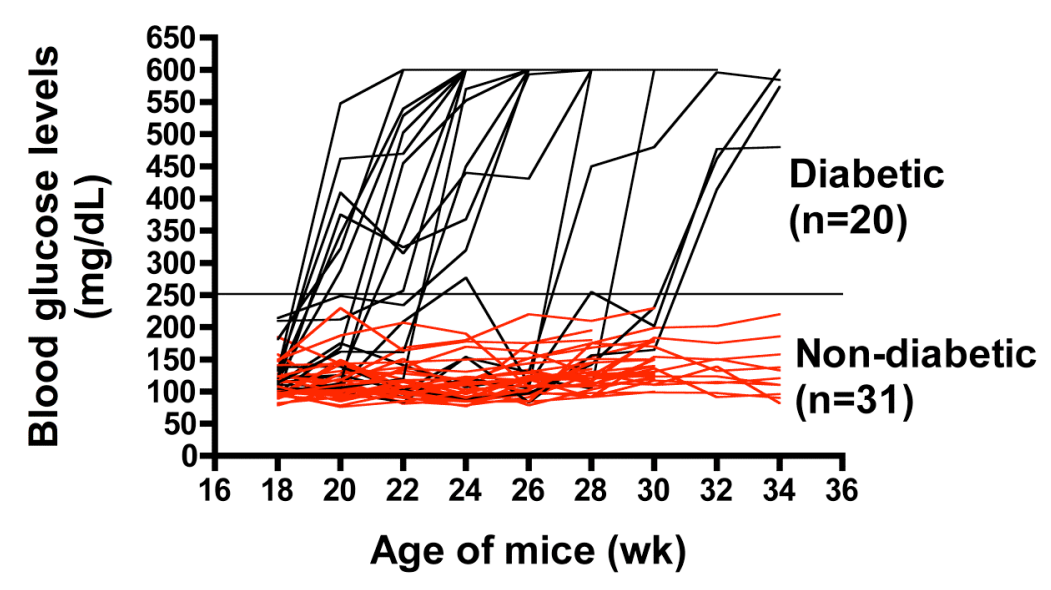

c

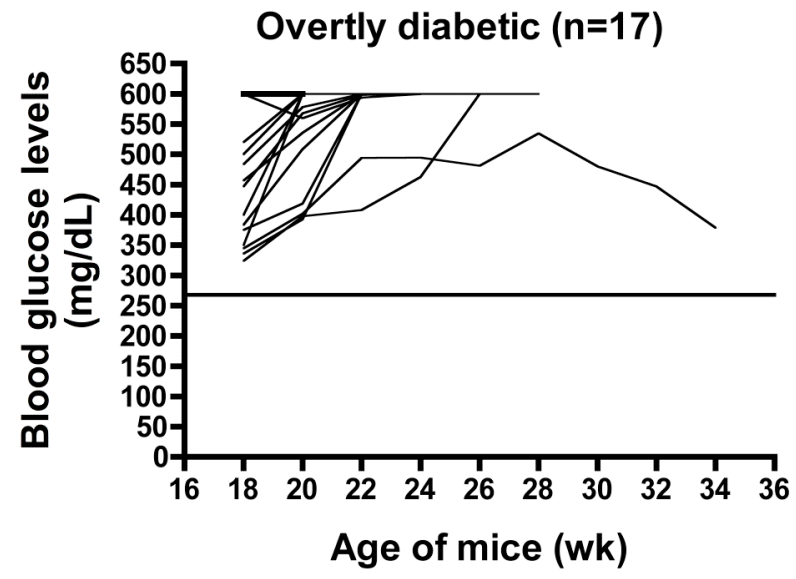


Fig. 2

a

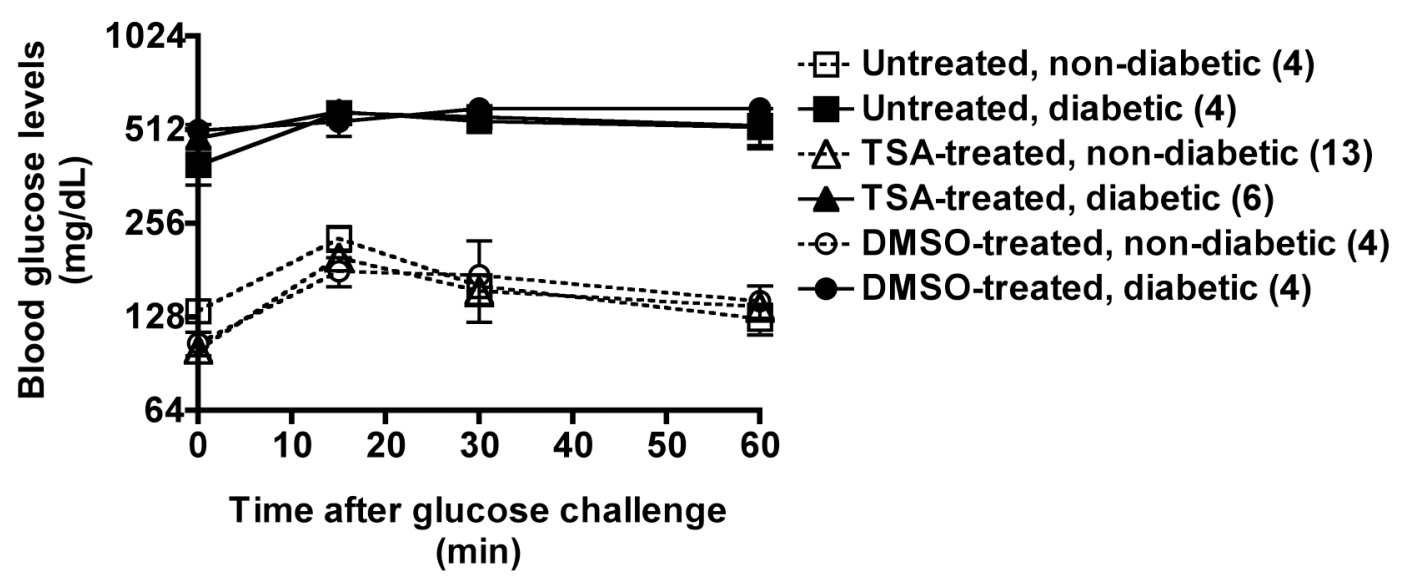

b

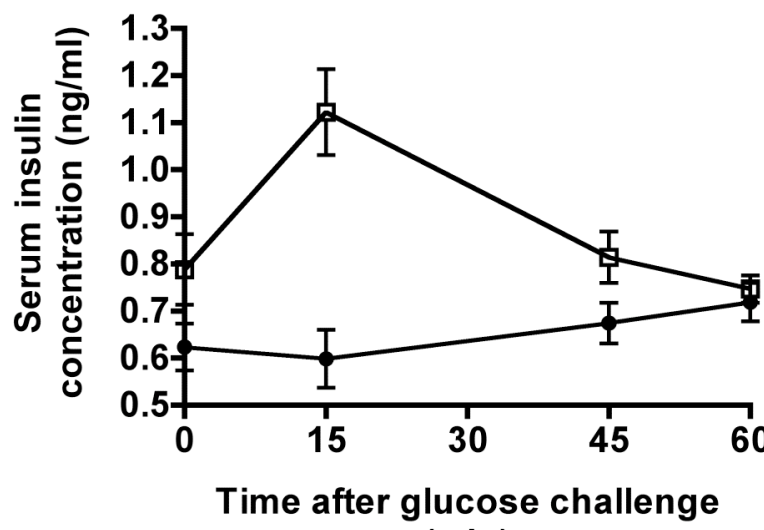

廿-Non-diabetic (8)

$\rightarrow$ Diabetic (6) (min) 
Fig. 3

a

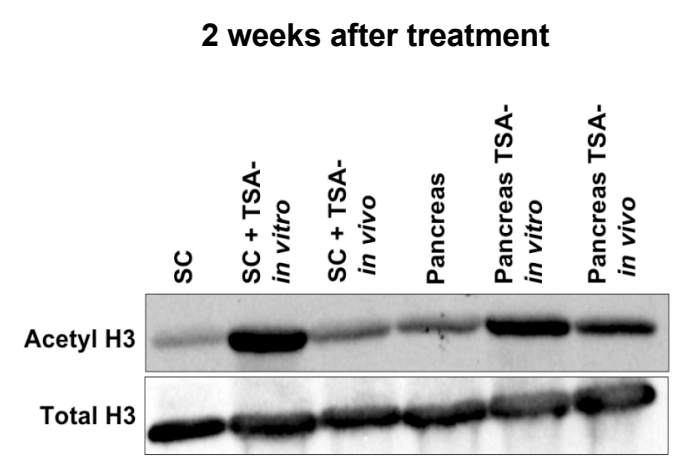

C

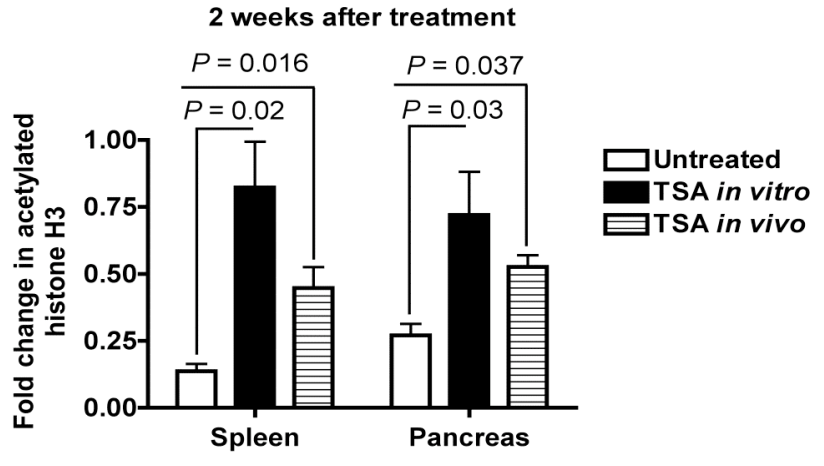

b

\section{2 weeks after treatment}

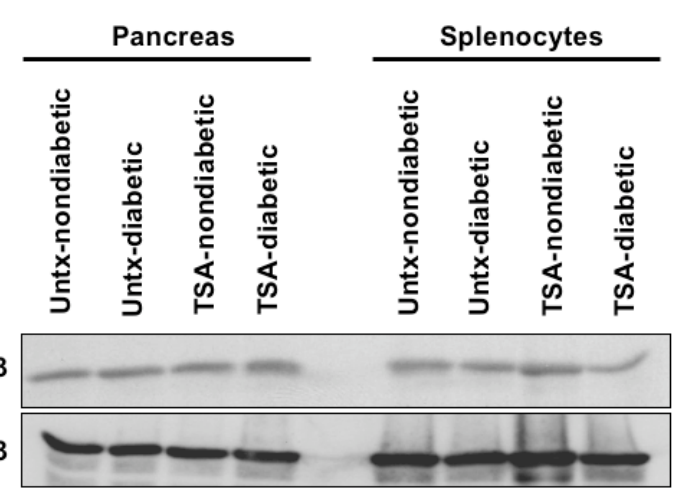

d

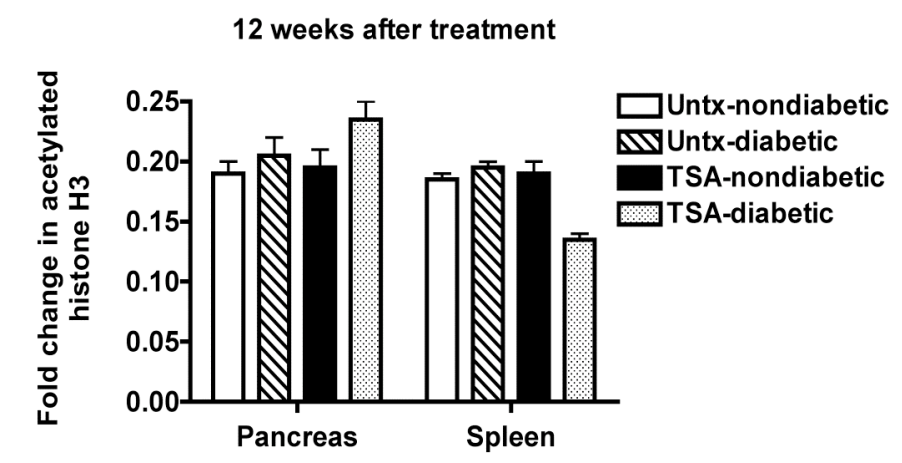


Fig. 4

a

Diabetic

$\square$ TSA-non-diabetic

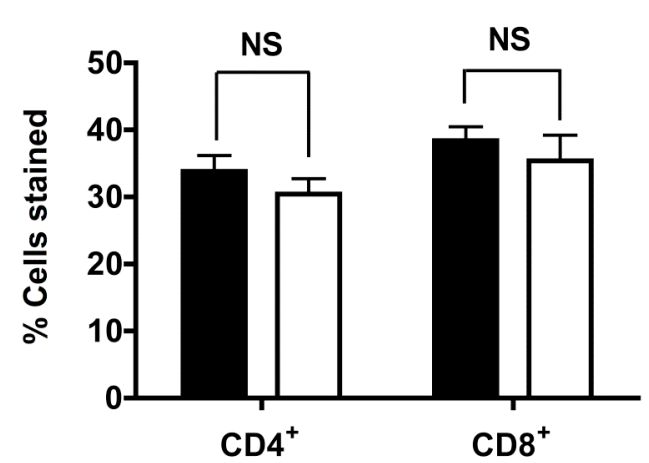

b

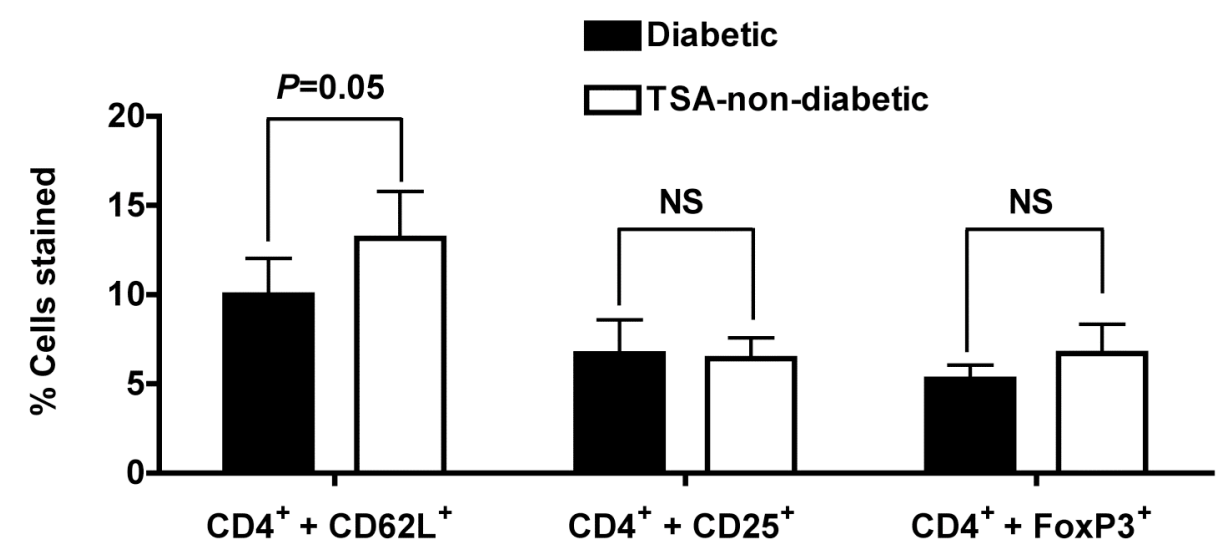


Fig. 5
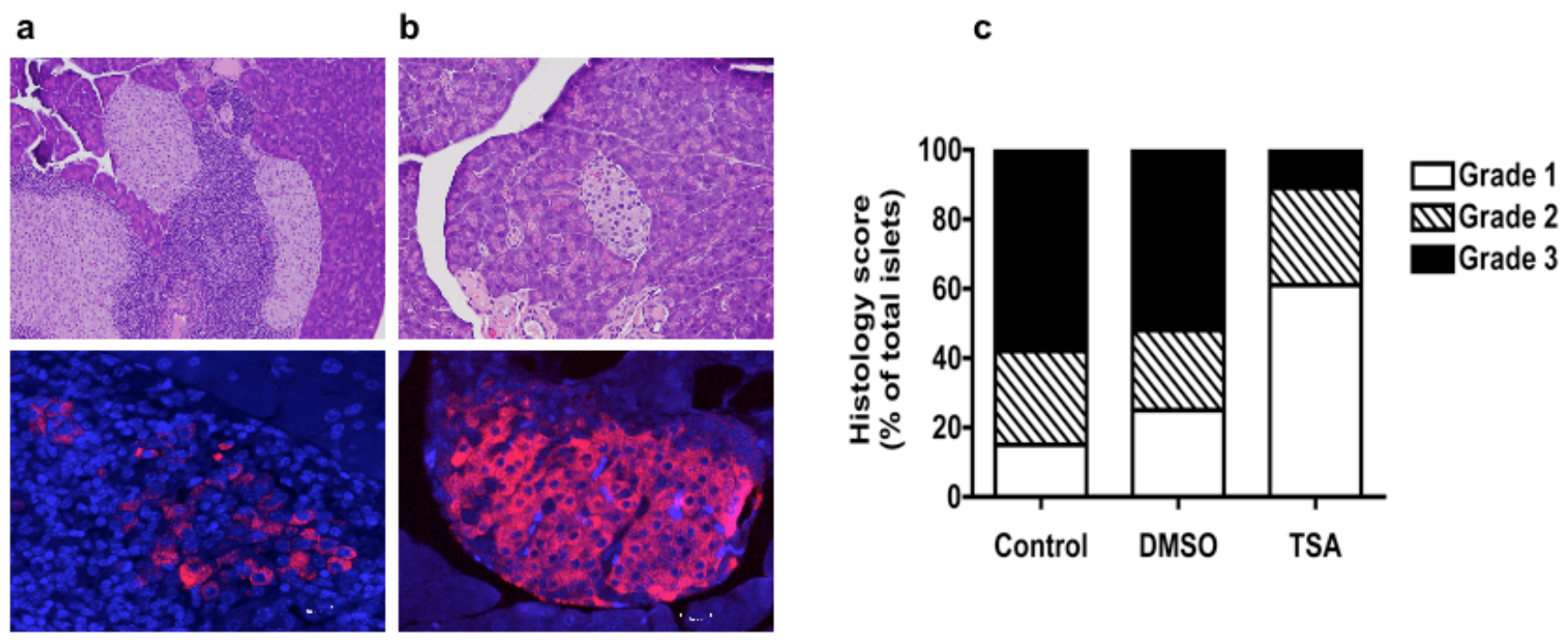
Fig. 6
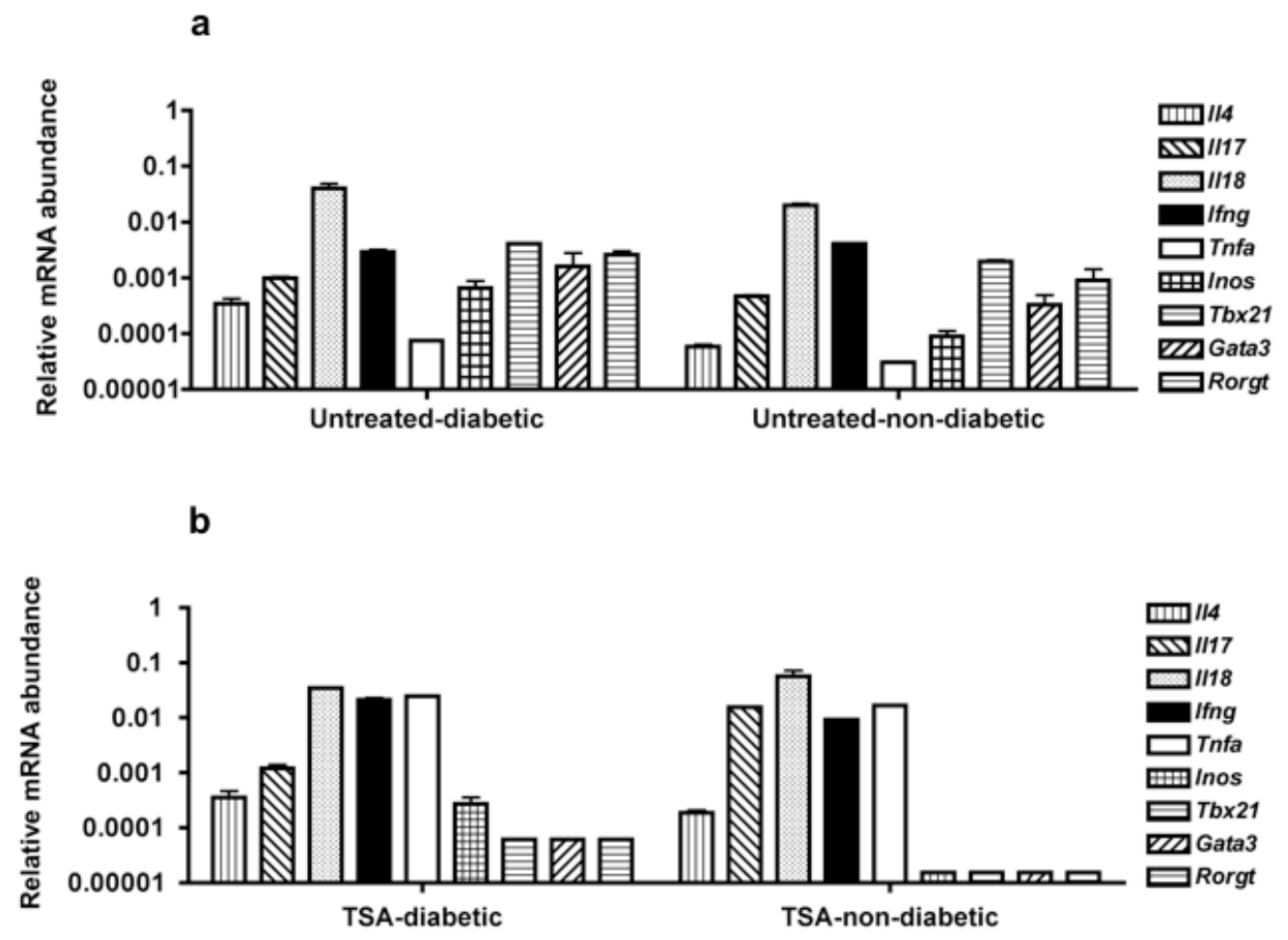
Fig. 7

a

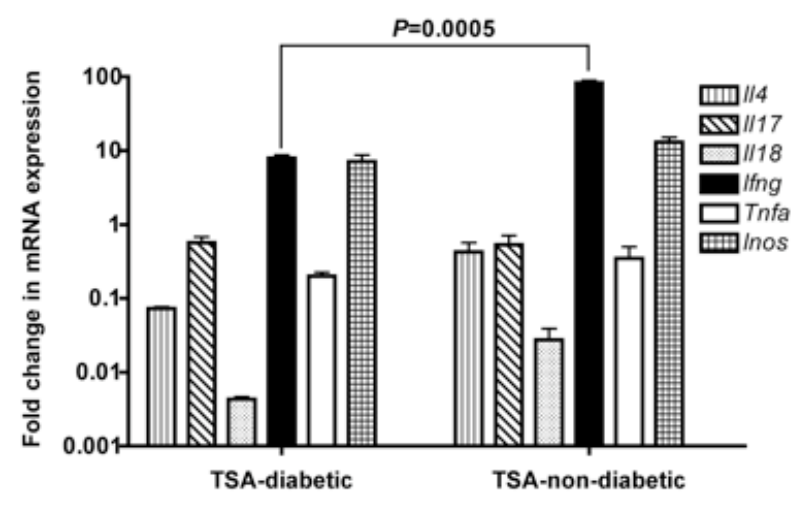

b

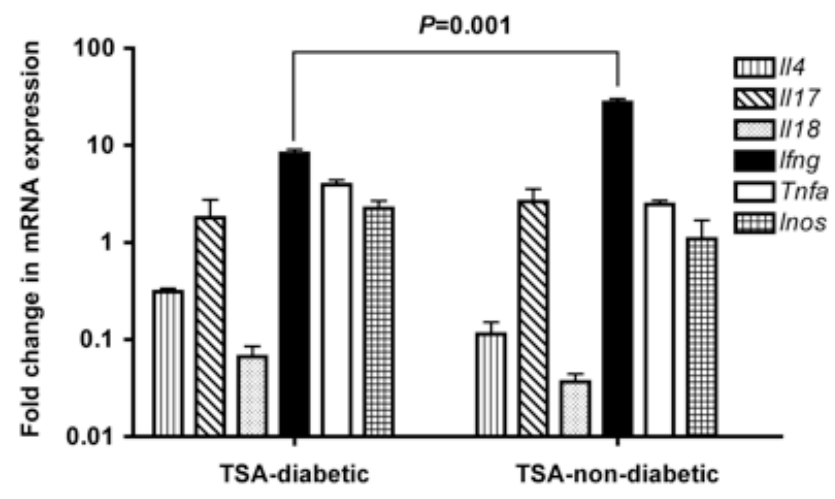

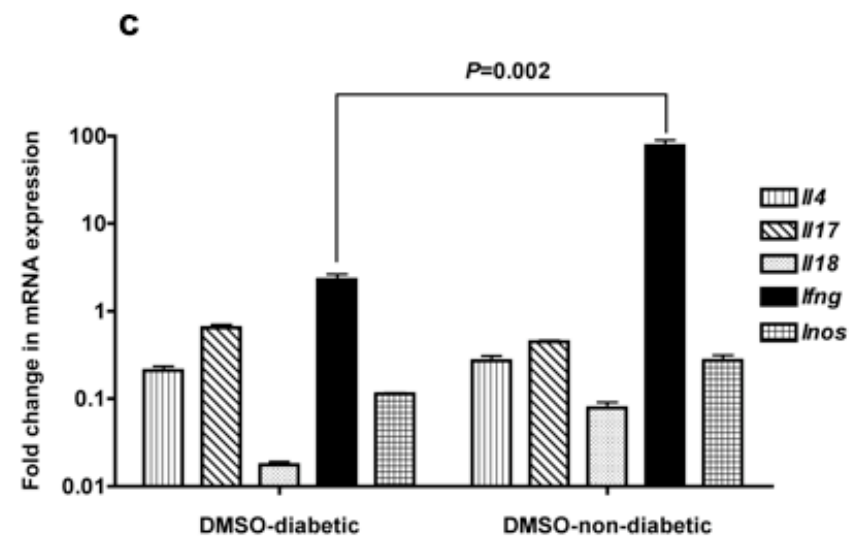


Fig. 8

a

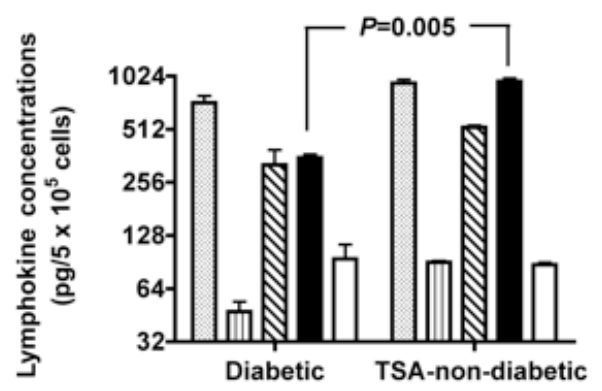

b

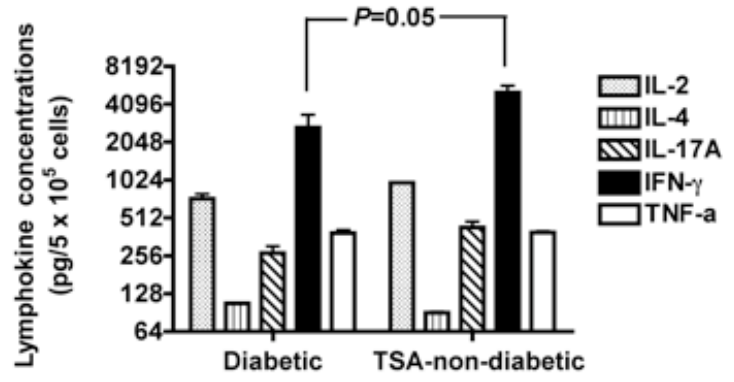


Fig. 9

a
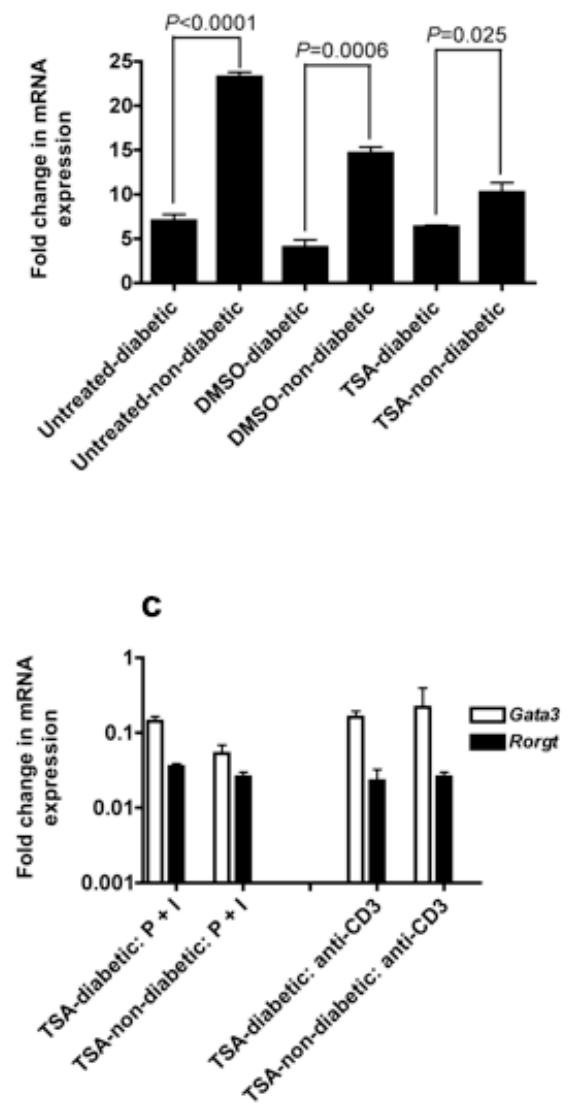

b

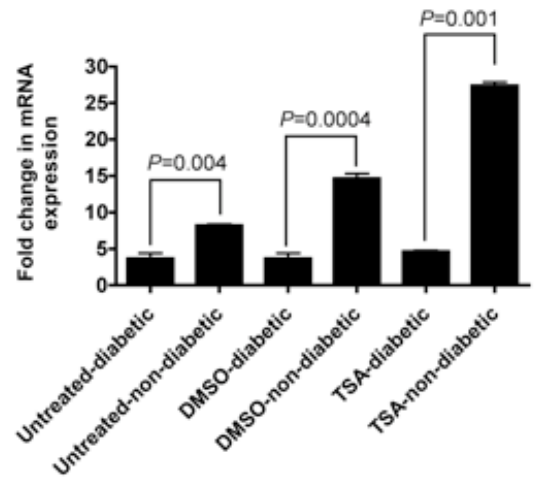

